\title{
MBE for Professor Helen Rodd
}

Professor Helen Rodd, a Consultant in Paediatric Dentistry at the University of Sheffield's School of Clinical Dentistry, has been awarded an MBE in the Queen's Birthday Honours, for her commitment to putting the needs of children at the heart of oral health research, and for her services to NHS dentistry.

Professor Rodd's leadership has changed the culture of research in the planning and delivering of the UK children's dental services, prioritising the child's perspective and experience. Through her commitment to undergraduate and postgraduate teaching, and specialist clinical training, Helen has mentored and enthused thousands of oral health professionals.

A graduate of Bristol University (BDS Hons 1988), Helen joined Sheffield University as a clinical lecturer in 1992. Her early research years were entirely laboratory-based. Her 2000 $\mathrm{PhD}$ thesis studied the markers of pain and inflammation in extracted primary and permanent teeth. This body of work was pivotal in demonstrating that primary teeth have similar pain receptors to permanent teeth, challenging the misconception that local anaesthetic was not necessary when drilling primary teeth.

Helen experienced her own lightbulb moment on returning to full time clinical work, where she was struck by the lack of research into children's views of their dental conditions and care. She became a firm advocate for child involvement, using participatory activities such as games,

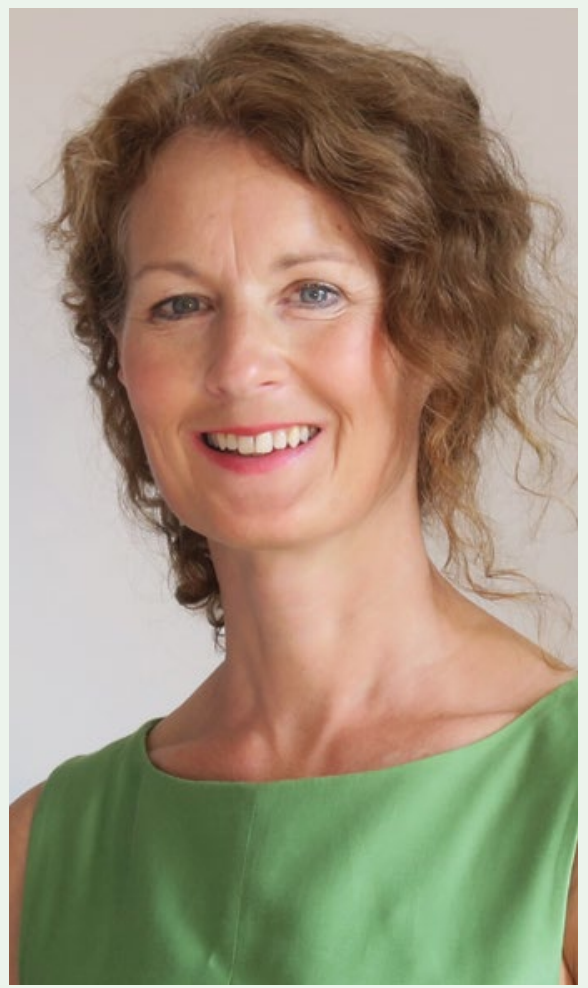

video diaries, and role play to explore their experiences.

Further research, into enamel defects and traumatic dental injuries, took into account the psychosocial impacts on children themselves. If they were made to feel selfconscious, or were being bullied, Helen wanted to know, to ensure that their social needs also influenced their treatment.

Promoted to Professor of Paediatric Dentistry in 2006, Helen's next round of research was prompted by the worrying number of children having dental extractions under general anaesthetic. She decided to explore the potential of cognitive behavioural therapy (CBT) to help children cope without undergoing a general anaesthetic.

Helen was part of a multi-disciplinary team, led by Zoe Marshman, Professor of Dental Public Health, also at the University of Sheffield, which was awarded NIHR funding for a study which led to the development of an innovative guided selfhelp CBT resource for children, 'Your teeth you are in control'.

This CBT resource went on to receive several regional and national awards for patient information innovation and is being used to help children with dental anxiety in dental services throughout the UK.

Professor Rodd's contribution to the British Society of Paediatric Dentistry (BSPD) has been immense, and her key roles have included President (20102011); Chair of BSPD's Commissioning Group (2010-2015); and Editor of the International Journal of Paediatric Dentistry (2005-2010).

Sarah McKaig, President of BSPD said: 'Helen is a role model for a whole generation of specialists and consultants in the art of child-centred paediatric dentistry. Going above and beyond the requirements of her role, she has helped shape a new approach to children's dentistry and her influence is felt around the globe.

Derek Maguire and Simon Wright were also recognised in the Queen's Honours and will be featured in the next issue.

\section{GDC publishes 2019 registration report}

On 1 October the General Dental Council (GDC) published a statistical report detailing the registration of dentists and dental care professionals, providing a snapshot of register data as of 31 December 2019.

The report shows that there were 42,470 dentists on the Register and 70,969 dental care professionals (DCPs). Of the DCP figure, 58,898 were dental nurses, followed by 7,563 dental hygienists as the next largest group. Clinical dental technicians (CDTs), the smallest group, numbered 375 .

The report provides statistics from the
GDC Registers, including the total number of dental professionals by title and the equality and diversity profile of the Registers. It also provides annual statistics relating to additions and removals, and the categories of those changes.

In analysis of the data, the regulator says it has identified an under-reporting of equality, diversity and inclusion (EDI) information by dental professionals, and is calling for professionals to check if their data is complete.

GDC Head of Regulatory Intelligence,

David Teeman, said: 'Whether dental professionals choose to share this EDI data is entirely a decision for them. However, of course, the more complete our EDI data, the better able we are to identify, explore, understand and respond to potential issues that correlate with EDI across everything the GDC does. It is for this reason that we are going to be talking more about the importance of this over the coming months'

The full report is available on the GDC's website: https://www.gdc-uk. org/about-us/what-we-do/the-registers/ registration-reports. 